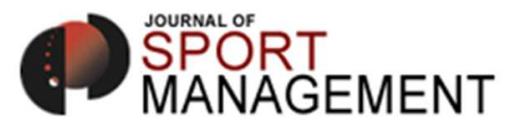

\title{
Epistemic Communities and Knowledge-Based Professional Networks in Sport Policy and Governance: A Case Study of the Canadian Sport for Life Leadership Team
}

\begin{tabular}{|r|l|}
\hline Journal: & Journal of Sport Management \\
\hline Manuscript ID & JSM.2016-0071.R1 \\
\hline Manuscript Type: & Article \\
\hline Keywords: & $\begin{array}{l}\text { Athlete Development, Case Study, Non-Profit Sport Organizations, } \\
\text { Organizational Politics, Policy Analysis }\end{array}$ \\
\hline \multicolumn{2}{|c}{} \\
\hline
\end{tabular}


Running head: CS4LLT: EPISTEMIC COMMUNITY

\begin{abstract}
This investigation examined how a network of knowledge-based professionals - the Canadian Sport for Life Leadership Team (CS4LLT) - as a newly emerging organizational form was able to influence the Canadian sport policy and governance process in an attempt to reshape Canadian sport. The analysis draws upon the epistemic community approach (Haas, 1992; Haas \& Alder, 1992) and empirical data collected as part of an in-depth case study examination into the leadership team and senior Sport Canada officials. The findings support the notion that the CS4LLT, as a network of knowledge-based professionals with legitimated and authoritative and policy relevant expertize, was able to influence the Canadian sport policy process through: (i) influencing key governmental actors by (re)framing policy-relevant issues and (ii) establishing knowledge/truth claims surrounding athlete development, which, in turn, enabled direct and indirect involvement in and influence over the sport policy renewal process. More broadly, the study draws attention to the potential role and importance of knowledge-based professional networks as a fluid, dynamic and responsive approach to organizing and managing sport that can reframe policy debates, insert ideas and enable policy learning.
\end{abstract}


Running head: CS4LLT: EPISTEMIC COMMUNITY

Epistemic Communities and Knowledge-Based Professional Networks in Sport Policy and

Governance: A Case Study of the Canadian Sport for Life Leadership Team

The Long-Term Athlete Development (LTAD) framework has been the subject of notable practitioner interest (e.g., Canadian Heritage, 2009; Duffy, Balyi, Aboud, Gregg, 2003; Stafford, 2005) and academic debate (e.g., Banack, Bloom, \& Falcão, 2012; Black \& Holt, 2007; Collins \& Bailey, 2013; Ford et al., 2011; Lang \& Light, 2010; Thibault \& Harvey, 2013) both domestically and internationally. Originally conceived by Balyi and colleagues in the early 1990s due to growing dissatisfaction with the superimposition of adult training and competition structures on adolescences, the LTAD framework is a multi-stage competition, training and recovery pathway designed to develop athletes 'from playground to podium' (Balyi et al., 2014). The framework has emerged primarily due to an increasing desire for many countries to ensure sustainable international sporting success (De Bosscher, De Knop, Van Bottenburg, \& Shibli, 2006) but also in an attempt to respond to the growing obesity epidemic. Within Canada, for example, the adoption of the LTAD framework by government occurred, in part, to attempt to respond to and realize the excellence and participation goals of the Canadian Sport Policy 1 (CSP1; 2002-2012), Canada's first national sport policy with bi-lateral agreements between the Federal and Provincial/ Territorial (F-P/T) Governments of Canada, and its successor policy, Canadian Sport Policy 2 (CSP2; 2012-2022) (Thibault \& Harvey, 2013; see also Comeau, 2013 for a specific discussion on the evolution of Canadian sport policy). In recent years, many sport organizations within Canada and other countries such as the United Kingdom and Australia have adopted the LTAD framework as the organizing framework for developing athletes to the extent that it could be described as the 'new orthodoxy' in athlete development. Yet curiously this widespread adoption of the LTAD framework has occurred even in spite of growing concerns 
Running head: CS4LLT: EPISTEMIC COMMUNITY

within the academic community regarding the validity and effectiveness of the framework (Black \& Holt, 2009; Côté, 2009; Collins \& Bailey, 2013; Ford et al., 2011; Frankish, 2011; Lang \& Light, 2010).

Within Canada, the LTAD framework has become the organizing framework and foundation for a much broader network or self-proclaimed 'social movement' entitled Canadian Sport for Life (CS4L) which, in a similar vein to LTAD, has materialized primarily due to a growing dissatisfaction and subsequent recognition of a plethora of shortcomings of the Canadian sport system (see Balyi et al (2005) and Norris (2010) for an in-depth discussion of these supposed systemic shortcomings). The CS4L network aims to improve the health, wellness, and sport experiences of all Canadians by improving performance and participation in sport and physical activity (Balyi et al., 2005). Both the LTAD framework and the CS4L network are led and supported by the Canadian Sport for Life Leadership Team (CS4LLT) - a group of knowledge-based professionals with a broad range of experience from across a variety of sectors who provide LTAD-related support and guidance to practitioners. ${ }^{1}$ Since its original conception in 2004, however, the leadership teams' role and responsibilities have evolved and expanded considerably. The leadership team was initially formed in late 2004 for the specific and sole purpose of developing a generic LTAD framework for Canada. Now, more than ten years on, the leadership team offers, a plethora of system wide consultation services to support LTAD integration and implementation within sport organizations, as well as organizing and facilitating a number of national and regional LTAD-related professional development workshops and

\footnotetext{
${ }^{1}$ Whilst every effort has been made herein to use the appropriate terminology in order to distinguish between LTAD as a specific athlete development framework, CS4L as a broader network of organizations/individuals that support the adoption and implementation of LTAD, and the CS4LLT as the group of knowledge-based professionals (or LTAD experts) responsible for the creation, promotion, and dissemination of the LTAD framework, such distinctions in reality are not clear. This is, in part, due to the fact these distinctions are often used interchangeably but also further complicated by the fact the CS4LLT decided in 2005-2006 to re-label and adopt the term CS4L (in favor of LTAD) in order to reflect the broadening of their own strategic remit. The adoption of the term CS4L in the latter part of this paper thus reflects the broadening of the CS4LLT's strategic focus.
} 
Running head: CS4LLT: EPISTEMIC COMMUNITY

conferences. The considerable expansion of their work over the past decade has led to the CS4LLT formalizing as federal not-for-profit organization in early 2015 ('Sport for Life Society'). Prior to this, however, the leadership team had operated in a relatively systematic and formalized manner akin to a sport organization, yet curiously enjoyed the flexibility and freedom associated with being a non-formalized organizational entity. This non-formalized approach is encapsulated in the leadership teams' decision to describe themselves as an 'un-organization'; a term that, according to select members of the leadership team at least, reflected the absence of bureaucratic structures that typify most sports organizations and its relative autonomy and independence from federal government.

Supported and enabled by the CS4LLT, many sports organizations across Canada (and abroad) have now adopted the LTAD framework. Most notably, Sport Canada - the federal government agency responsible for overseeing and delivering governments objectives in sport has invested approximately $\mathrm{C} \$ 1,500,000$ per annum to LTAD-related activities to support the integration and alignment of sport organizations and has officially adopted the LTAD framework as part of its own strategic and organizational planning (Canadian Heritage, 2009).

Consequently, all National Sport Organizations, the governing bodies primarily responsible for organizing and delivering national team programs and setting the rules and regulations of their respective sport, are now required through federal funding agreements (via Sport Canada) to incorporate LTAD principles within their strategic and operational processes in order to be eligible for federal funding ${ }^{2}$. Furthermore, and crucially here, in addition to being adopted and

\footnotetext{
${ }^{2}$ LTAD-related funding requirements include ensuring LTAD appropriate planning and provision, the production and implementation of a sport specific LTAD framework, and a full competition review in order to ensure that all programs and structures are developmentally appropriate in accordance with LTAD principles (Canadian Heritage, 2009).
} 
Running head: CS4LLT: EPISTEMIC COMMUNITY

implemented across the sporting delivery chain, LTAD/CS4L has also arguably been able to influence the highest levels of decision-making within Canadian sport by influencing the Canadian sport policy process, both in terms of generating new ideas (i.e., policy formulation) and supporting the delivery of policy objectives (i.e., implementation). In support of this contention, an independent evaluation of the Canadian Sport Policy $1^{3}$ (CSP1, 2002-2012; Canadian Heritage, 2002a) recognized LTAD/CS4L as the cornerstone contributor to the relative success of the policy (Sutcliffe, 2010). Additionally, LTAD principles and terminology such as Physical Literacy and Fundamental Movement Skills have also been explicitly adopted and incorporated into the Canadian Sport Policy 2 (CSP2, 2012-2022; Canadian Heritage, 2012). In sum, the above (albeit anecdotal) evidence supports the viewpoint that LTAD/CS4L has begun to infiltrate, influence, or at least become a part of, the highest levels of decision-making Canadian sport within Canadian sport.

In recognition of the above, our analysis seeks to examine how the CS4LLT - as a newly emergent organizational form that has emerged in response to federal governments' desire to systematically develop athletes in order to produce international sporting success - was able to influence the Canadian sport policy and governance process by answering the following research question: How has the CS4LLT been able to influence the Canadian sport policy and governance process? To this end, we draw upon the epistemic community approach to make sense of the CS4LLT as a newly emerging organizational phenomenon (pre-formalization; i.e., between 2004 and 2015) that was initially designed to overcome specific technical high performance-related athlete development issues within Canadian sport, but has since morphed to a much broader, more encompassing phenomenon that is now being used to achieve a plethora of governmental sporting objectives. 
Running head: CS4LLT: EPISTEMIC COMMUNITY

This study consequently makes the following threefold contributions to the sport management/policy literature. First, we extend recent work that has sought to theorize the mesolevel sport policy process (e.g., Comeau, 2013; Green \& Houlihan, 2005; Houlihan, 2005; Houlihan, Bloyce, \& Smith, 2009) by offering the epistemic communities approach as a useful alternative theoretical approach to understand and explain sport policy change. The strength of the epistemic community perspective, we argue, is its ability to explain how knowledge can be used in order to gain power and influence over the policy process. Second, this case study examines how a network of knowledge-based professionals - the CS4LLT- as a newly emerging organizational form was able to influence the Canadian sport policy and governance process in an attempt to reshape Canadian sport. In doing so, we directly respond to Thibault and Harvey's (2013) call for more research into contemporary policy-related developments within Canadian sport and Misener and Misener's (2015) more recent call for more studies into new organizational-like forms. Our case analysis of the CS4LLT draws attention to the potential role and importance of knowledge-based professional networks as a fluid, dynamic and responsive approach to organizing and managing sport that can reframe policy debates, insert ideas and enable policy learning. Third, this investigation also contributes to the more specific LTADrelated debates (e.g., Black \& Holt, 2009; Côté, 2009; Collins \& Bailey, 2013; Ford et al., 2011; Frankish, 2011; Lang \& Light, 2010) that have gained traction in recent years by providing an insight into how and why the framework, despite being comparatively under-researched, has been adopted by governments and the sporting communities at large as the de facto organizing approach for conceptualizing athlete development both domestically and abroad.

\section{Epistemic Communities}


Running head: CS4LLT: EPISTEMIC COMMUNITY

The investigation draws upon the epistemic community approach to examine how the CS4LLT has been able to influence the Canadian sport policy and governance process. The epistemic community approach was originally formulated by Peter M. Haas in 1992 as part of a special issue in International Organization (Haas \& Alder, 1992). The approach emphasizes the role of knowledge-based experts in the co-ordination and formulation of the policy making process - particularly for decision making instances that are characterized by technical complexity and uncertainty. For Haas (1992), an epistemic community "is a network of professionals with a recognized expertize and competence in a particular domain or issue area" (p. 3). Central to the perspective is the recognition that key policy/decision-makers (typically but not exclusively ministers and senior civil servants) within the policy making process are constrained in that they operate under conditions of uncertainty, complexity, limited knowledge and restricted/bounded temporality. As a result of these constraints, decision-makers (within government) often turn to non-governmental actors for ideas and advice in order to reduce levels of uncertainty, with epistemic communities being one potential source of information.

The epistemic community perspective has become firmly embedded in the social science lexicon and is empirically 'well-travelled' (Dunlop, 2012). The perspective has been applied to a number of contexts both domestically and internationally including: nuclear arms control (Adler, 1992), trade services (Drake \& Nicolaidis, 1992), whaling and environmental protection (Haas, 1989; Peterson, 1992), post-war settlements (Ikenberry, 1992), the construction of world politics (Antoniades, 2003) and more recently the role of religious actors in conflict resolution (Sandal, 2011). Yet despite its varied application within the mainstream public administration and international relations literature (cf Adler, 1992; Adler \& Haas, 1992; Cross, 2013; Dunlop, 2012; Haas, 1992; Ikenberry, 1992; Peterson, 1992; Sebenius, 1992; Toke, 1999), scholars have 
Running head: CS4LLT: EPISTEMIC COMMUNITY

noted the continued lack of theoretical elaboration or development of Haas' original conception (Cross, 2013; Dunlop, 2012). Furthermore, it is also apparent that epistemic communities have received little attention within sport management/policy scholarship (for partial treatments see Green \& Houlihan, 2005; Houlihan, 2005). The paucity of discussions surrounding epistemic communities within sport to date is even more surprising given that some mainstream public policy scholars have suggested that epistemic communities are becoming progressively more prevalent and influential actors (Cross, 2013; Dunlop, 2012). As such, and in echoing the recent sentiments of mainstream political science and international relations scholars (e.g., Cross, 2013; Dunlop, 2012), it is argued here that the "utility and explanatory power of the concept [of epistemic communities] has been seriously under-recognised" (Cross, 2013, p. 159) within sport management/policy scholarship.

To elaborate further on the approach itself, according to Haas' (1992), epistemic communities can help decision-makers in the following ways; first, they can help clarify the boundaries of a particular societal problem by identifying its causes and consequences. Second, these knowledge-based experts can also support decision-makers by shedding light on the complexity of a particular issue at hand, the likelihood (or cost) of outcomes for particular courses of action or inaction. Third, epistemic communities can also support decision-makers through redefining a particular problem; this can be in the form of preconceived interests or interests that have not previously considered. Fourth, and critically, such networks of professionals have a role to play in the framing or reframing of problems that facilitate collective debate. Hence, epistemic communities can have a potentially significant role in the framing of a problem or issue in a manner that may result in particular interests being privileged over others. Fifth and finally, epistemic communities also help in the formulation of policies; this may be in 
Running head: CS4LLT: EPISTEMIC COMMUNITY

the form of broader support for a particular policy in order to justify a course of action taken by government or through working out the more specific details of a policy and identifying the actions that need to be taken to implement it effectively.

The benefit of the epistemic community approach compared to other meso-level theoretical policy perspectives that have been used to examine sport (Houlihan, 2005; see also Green \& Houlihan, 2005; Houlihan et al., 2009) lies in its ability to explain how and why nonstate actors are able to influence the policy process even in the absence of formal structures or mechanisms in which to do so and its utility in demonstrating how knowledge - particularly expert-knowledge - can be used to gain power and influence over the policy-making process. In particular, the approach emphasizes the role of knowledge-based professionals in formulating policy, i.e., once an issue has been identified, how knowledge-based professionals support and enable decision-makers to choose a particular course of action, especially when decision makers are unfamiliar with the technical aspects of a specific problem or issue (i.e. athlete development). It is the epistemic communities' emphasis on the state and non-state actor relationship during the formative stages of the policy process and how the latter can co-ordinate and organize themselves in order to influence the former, that makes the epistemic community approach particularly valuable in explaining the role and influence of CS4LLT as a newly emergent organizational form within Canadian sport.

\section{Methodology}

A holistic, single-case study research design (Yin, 2013) was adopted to examine the CS4LLT. A case study approach is "an empirical inquiry that investigates a contemporary phenomenon (the 'case') in depth and within its real-world context, especially when the boundaries between the phenomenon and context may not be clearly evident" (Yin, 2013, p. 16). 
Running head: CS4LLT: EPISTEMIC COMMUNITY

Case study research is increasingly prevalent within sport management and is becoming one of the most commonly used methodological approaches within the field (Andrew, Pedersen, \& McEvoy, 2011). The strength of this approach lies in its ability to explain contemporary phenomenon whereby the 'real-life' causal links are complex and unclear (Eisenhardt \& Graebner, 2007; Yin, 2013). Such complexities are particularly evident, for example, when attempting to delineate and distinguish LTAD as a specific athlete development framework, CS4L as a broader network or 'social movement' and the CS4LLT as a group of knowledgebased professional experts responsible for the creation and dissemination of LTAD and leadership over CS4L. The adoption of a holistic case study methodology is therefore a particularly well-suited approach to examine the CS4LLT as a contemporary and constantly evolving organizational-like form that operates within an equally ever changing and increasingly complex sporting landscape.

\section{Sampling and Procedure}

Primary data were collected using semi-structured interviews with the entire CS4LLT $(N=17$; Table 1$)$ and senior Sport Canada officials $(N=5)^{4}$. Informants were purposefully selected on the basis of having in-depth knowledge of the CS4LLT and the adoption of LTAD by government (via Sport Canada). This approach is also referred as elite sampling within the methodological literature (Mayan, 2009) whereby leading experts or those who hold positions of relative power and knowledge are selected to inform an inquiry. Whilst the researcher acknowledges the likelihood that the CS4LLT in particular have an inherent positive bias and worldview with regards to their own contribution and role within Canadian sport, they

\footnotetext{
4 This article draws upon empirical data collected from a much larger unpublished doctoral study (reference omitted for review purposes) that examined the role of the CS4LLT within Canadian sport. Specifically the larger study examined (i) the CS4LLT's role and influence on Canadian sport policy (ii) its relationship with Sport Canada, and (iii) its influence on National Sport Organizations.
} 
Running head: CS4LLT: EPISTEMIC COMMUNITY

nonetheless were recognized as the most knowledgeable experts in regards to CS4LLT's operations and practices.

Face-to-face interviews were preferred and all interviews took place between January and September 2013. Ten interviews were conducted at the C4SL's National Summit held in Gatineau, Ottawa (28 ${ }^{\text {th }}$ January- ${ }^{\text {st }}$ February, 2013). The CS4L National Summit was deemed a particularly appropriate location for interviewing as the CS4LLT and Sport Canada officials converge in Ottawa annual basis to attend pre-summit workshops, meetings and the summit itself. Two interviews took place on university campuses and five were conducted electronically using the software program Skype. Interviews ranged between 31 and 125 minutes in length and were digitally recorded and transcribed verbatim. The interview process produced a total of 824 double-spaced pages of transcript deemed appropriate for further analysis. Due to our study specific centring on the CS4LLT leadership team, it was not deemed appropriate or necessary to fully anonymise participants as they are directly identifiable from public domains (via the web), nonetheless, in order to ensure partial anonymity all participants were assigned a generic job role and a random number allocation (e.g., CS4LLT Member \#7; Senior Sport Canada Official \#18). Participants were also sent a copy of their interview transcript within two weeks following the interview. This not only ensured greater accuracy of the data collected but also acted as a form of 'member checking' (Mayan, 2009) whereby the researcher was able to verify the participants views had been fully captured during the interview and also enabled participants the opportunity to rephrase and/or remove data as they deemed appropriate (2/23 respondents requested minor transcript adjustments).

$* * *$ insert table 1 about here ${ }^{* * *}$ 
Running head: CS4LLT: EPISTEMIC COMMUNITY

Consistent with Yin's (2013) case study approach, a range of secondary sources were also collected. Additional sources included organizational documents (i.e., CS4LLT, Federal Sport Policy and Sport Canada produced LTAD-related documentation), CS4L National Summit attendance data (2006-present), and research notes from attending a series of workshops, conferences, mini-summits and CS4L-related meetings over a three-year period (2011-2014) (see table 2 for an overview of data sources). Secondary sources were not thematically analysed per se but were used during the early stages of the research process to ensure that the primary researcher was fully-immersed in the research context and then later on to triangulate and verify the primary data and findings during the latter stages of the research process (Patton, 2002).

\section{$* * *$ insert table 2 here $* * *$}

\section{Data Analysis}

The interview process produced a total of 824 double-spaced pages of transcript deemed appropriate for further analysis. The data analysis process followed a modified version of Miles, Huberman, and Saldaña's (2013) analytical approach. All data were collected and analyzed by the first author. Consistent with Miles et al.'s (2013) approach, data collection and analysis occurred concurrently with all interviews read and then re-read to ensure full immersion. Data were initially analyzed through an inductive coding process to produce first-order codes from raw data (e.g., "we published the generic LTAD booklet in Ireland" = LTAD promotion abroad (first order code)). This was followed by a higher-order pattern matching process in order reduce the data (e.g., LTAD promotion abroad - athlete development reframing (second-order code)). First-order and higher-order codes were subject to an iterative axial coding process whereby codes were constantly refined throughout the collection and analysis process. Coding in this manner thus required multiple rounds of analysis. These higher-order codes were then 
Running head: CS4LLT: EPISTEMIC COMMUNITY

deductively applied to Haas's (1992) epistemic communities' framework (e.g., athlete developing framing $=$ recognising and reframing athlete problem (theme) $)$ In this regard, the epistemic community approach was employed as a lens in which to make sense of the interview data in order to explain how the CS4LLT has been able to influence the Canadian sport policy and governance process. The data converged into three broad themes that conformed closely to and were consist with Haas' (1992) framework: (i) the recognition and reframing of policy problems, (ii) establishing knowledge/truth claims and (iii) direct and indirect influence over policy formulation and implementation.

\section{Findings}

This section examines how the CS4LLT has been able to influence the Canadian sport policy and governance process. Primarily due to space constraints, the following discussion centres on the more pertinent policy-related findings from the aforementioned larger investigation (reference omitted for review purposes). More specifically, the discussion below examines how the CS4LLT - as an epistemic community - has been able to: influence government actors through the (re)framing of policy relevant issues and establish knowledge/truth claims surrounding athlete development, which, in turn, enabled the direct and indirect influence the Canadian sport policy renewal process. The analysis below is ordered in a chronological fashion and focuses on some of the key socio-political events in the CS4LLT's development over the past decade.

\section{(i) Recognizing and reframing the athlete development 'problem'}

\section{Problem Recognition: CSP1 and uncertainty}

The origins of LTAD/CS4L, at least in policy terms, can be traced back to the Canadian Sport Policy (CSP1; 2002-2012). More specifically, it originated from CSP1's excellence goal, 
Running head: CS4LLT: EPISTEMIC COMMUNITY

which stated that by 2012 "Canadian athletes and teams are systematically achieving [emphasis added] world-class results at the highest levels of competition through fair and ethical means" (Canadian Heritage, 2002a, p. 4). The need for systematic athlete development was also identified as a key political priority within CSP1 which called for "for a systematic, analytical, and collaborative approach to the development of high performance athletes" (Canadian Heritage, 2002a, p. 9), and "greater attention will be devoted to a systematic approach to ensure the development of a constant stream of world-class athletes, coaches and officials" (Canadian Heritage, 2002a, p. 17).

This recognition was further reinforced by the Federal-Provincial/Territorial (F-P/T) Sport Committee Excellence Working Group that was formed after the publication of CSP1 in order to carry out the specific high performance-related actions of the F-P/T priorities for collaborative action (2002-2005; Canadian Heritage, 2002b). Of particular note, was the involvement of Richard Way (now leader of the CS4LLT) as a provincial government representative at the time, and one of nine members that formed the original working group. The groups' efforts culminated in the publication of the Brisson Report (Brisson, 2004) which recommended, inter alia, the system wide adoption of the LTAD framework as a priority for Canadian high performance sport to suggest "that the entire sport system take a Long-Term Athlete Development (LTAD) approach” (Brisson, 2004, p. v). The LTAD-related recommendations of the Brisson Report would be a critical step towards the formal endorsement and adoption of the LTAD framework by F-P/T Sport Ministers later that year.

The broader outcome of the CSP1 process and the inter-governmental developments that would follow was a growing recognition by government and the sporting community at large that Canada had an athlete development 'problem' with a degree of uncertainty about how exactly to 
Running head: CS4LLT: EPISTEMIC COMMUNITY

resolve it. For Haas (1992), it is during periods of uncertainty that decision makers are most likely to turn to epistemic communities for advice - particularly with regards to increasingly technical and scientific domains such as athlete development. Uncertainty, therefore, seems to be critical ingredient, or the necessary scope condition as Cross (2013) terms it, for the emergence and development of epistemic communities within policy domains. It should be acknowledged at this stage that none of the interviewees explicitly characterized the post-CSP1 period as being a period of relatively high uncertainty. One interpretation could therefore be that uncertainty was not present in prior to CS4LLT's development. Cross (2013), however, provides a useful elaboration on Haas's (1992) original narrowly-defined notion of uncertainty in that "uncertainty is everywhere, not just in circumstances that might be labelled after the fact as having constituted major crises" (p. 151). For Cross (2013), then, uncertainty is a pervasive "normal state of affairs" (p. 151) and can be understood as a permanent feature of governmental thinking, rather than the product of a 'period of crisis' per se. From this perspective, the emergence and development of the CS4LLT should be contextualized within the broader political developments that were occurring within Canadian sport at the time. Not only has Canadian sport historically been characterized as a highly fragmented pluralist network (Barnes et al., 2007; Comeau, 2013), but CSP1 (2002-2012) emerged, in part, to attempt to 'deal' with ongoing broader tensions regarding the role of federal-provincial/territorial governments' in sport and sport organizations and the ongoing debate regarding whether or not Canada should continue to prioritize high performance sport over other social objectives (Green \& Houlihan, 2005; Thibault \& Harvey, 2013). These broader tensions would have been brought into focus during the CSP1 policy process and given further impetus as a result of Canada's successful bid to host for the XXI Olympic Winter Games. In relation to the CS4LLT specifically, these broader historical tensions and 
Running head: CS4LLT: EPISTEMIC COMMUNITY

contemporary policy-related developments would have contributed to the creation of a permissive climate in which decision-makers would have been particularly susceptible to ideas surrounding increasingly policy-relevant and high politics issues such as how best to systematically develop high performance athletes.

\section{Problem Reframing: CS4LLT and inter-governmental decisions}

It was during this time (i.e., 2002-2004) that Balyi and colleagues began promoting and implementing LTAD abroad. It should be noted at this conjuncture that Balyi and colleagues had already spent the best part of a decade promoting LTAD domestically with relatively modest success that was largely confined to the intrigue and interest of a handful of high performance coaches operating primarily (although not exclusively) within the province of British Columbia. In August 2003, however, Pat Duffy, the then Director of Ireland's National Coaching Training Centre, invited Istvan Balyi to give a presentation at the 7th National Irish Sports Forum. As CS4LLT member \#9 recalled:

Pat [Duffy] found Istvan on the Internet and asked him to come over to Ireland for the Irish sports forum and give a presentation on LTAD, and it seems to be the right place, and the right time, the right people, because Ireland started to buzz about LTAD (CS4LLT Member \#9 02/15/13).

One of the direct outcomes of Istvan's presentation to the Irish Sport Forum was that he and colleagues were contracted by Ireland's National Coaching Training Centre to produce a generic LTAD for Ireland (Duffy et al., 2003). It was during this period Balyi and colleagues were also contracted by Sports Coach UK to develop LTAD-related coaching materials, as well as to develop LTAD sport specific frameworks for Irish Rugby and British Swimming.

It would be only after LTAD had been tried and tested abroad that it would begin to gain greater interest and traction domestically, most notably greater interest and traction within Sport Canada. As a CS4LLT member recalled, "What happened is we published the generic LTAD 
Running head: CS4LLT: EPISTEMIC COMMUNITY

booklet in Ireland, and Sport Canada got a copy of it and they became very much interested in the possibilities of the document" (CS4LLT Member \#9 02/15/13). Sport Canada officials echoed this perspective,

Istvan and Richard had done work in other countries and had been positively received and I think a lot of Canadian sport leaders saw that if this is being embraced by other countries and these are Canadians [who] are doing this, are we [Sport Canada] missing the boat by not being on board here? (Senior Sport Canada Official \#18 07/22/13).

Similarly, "In some ways we [Sport Canada] got involved a little bit after the fact, so Istvan and Richard and some others had been very busy going out around the world, going to do work in the UK and Ireland and all kinds of places selling CS4L” (Sport Canada Official \#22 01/17/13).

Evident from the above accounts, and rather ironically, the work of Balyi and colleagues abroad between 2002 and 2004 should be recognized as an important and necessary step towards the FP/T Government's decision to adopt the LTAD framework within Canada. Thus without the selling, promotion, demonstration, and legitimization of the LTAD framework overseas, it would have been unlikely that the framework would have been adopted and endorsed by F-P/T Governments (via Sport Canada) in April 2004.

Between 2004 and 2006, a series of inter-governmental decisions were made that resulted in the system wide adoption of LTAD by F-P/T governments. On the $29^{\text {th }}$ April 2004, F-P/T Sport Ministers, the federal-provincial/territorial minsters responsible for sport, met in Québec City to discuss, amongst other elements, the formal adoption and dissemination of LTAD across Canada. The Québec conference had three major CS4L-related outcomes, the first of which was a bi-laterally agreed commitment to adopt and implement LTAD across Canada. In this manner, not only was the Québec conference an integral step for the 'buy-in' of government ministers in general, but it also signified a political commitment and willingness on behalf of two levels of governments (i.e. federal and provincial/territorial) within Canada to develop LTAD across the 
Running head: CS4LLT: EPISTEMIC COMMUNITY

country. Second, minsters also agreed to provide the necessary funding, through Sport Canada, to produce a generic LTAD framework to serve as a template to assist sport organizations and provincial/territorial governments in developing LTAD appropriate programming. This initial investment by ministers would eventually lead to the publication of the Canadian Sport for Life resource document a year later (Balyi et al., 2005) - a document that remains the seminal resource document outlining the fundamental principles of LTAD to this day (see below). The third and final outcome of the Québec conference, and as a direct result of the decision to create a generic LTAD framework, was the formation of the then 'LTAD Expert Group' which was contracted by government with the sole purpose of producing the generic LTAD document. The group initially consisted of four members (Istvan Balyi, Richard Way, Charles Cardinal and Stephen Norris; see Table 1 for an overview) who would meet in Ottawa later that year with the sole purpose of producing a generic LTAD document for Canada.

The collective outcome of the abovementioned intergovernmental developments was the support and legitimization of LTAD framework by the Canadian Federal Government (via Sport Canada). For Haas (1992), "it is the political infiltration of an epistemic community into governing institutions which lays the groundwork for a broader acceptance of the community's beliefs and ideas about the proper construction of social reality" (p. 27). F-P/T Ministers' decision to adopt LTAD, over other arguably better researched athlete development frameworks, would have therefore legitimized and positioned the CS4LLT as the experts who sport organizations could turn to for advice due to high levels of uncertainty regarding how to implement LTAD. Furthermore, it would be through the slow and steady realization by both government and the CS4LLT that implementation of LTAD within sport organizations would take considerable time to achieve; consequently the CS4LLT effectively ensured their own role 
Running head: CS4LLT: EPISTEMIC COMMUNITY

as a support network for Canadian sport organizations in LTAD-related matters for the foreseeable future.

\section{(ii) Establishing knowledge/truth claims surrounding athlete development}

According to the epistemic community approach, epistemic communities influence decision-makers and the policy process by producing knowledge/truth claims that overtime help frame policy-relevant issues for collective debate (Dunlop, 2012; Haas, 1992). Concurrent to the LTAD/CS4L-related inter-governmental developments discussed above, a number of more specific LTAD/CS4L-related developments occurred that, over time, would enable the CS4LLT to establish knowledge/truth claims within the athlete development domain. Most apparently, CS4LLT published a generic framework along with a number of LTAD-related supplementary materials and created annual LTAD Workshop/CS4L Summit.

\section{$* * *$ insert table 3 about here $* * *$}

\section{The Generic LTAD Framework and Supplementary Material}

In 2005, the then LTAD Expert group published a generic LTAD framework for Canada (Balyi et al., 2005). The generic LTAD framework was a 66-page resource paper entitled the 'Canadian Sport for Life: Long-Term Athlete Development Model'. The consultation paper was published through the Canadian Sport Centre Calgary with the two-fold intention of providing a generic framework (i.e. template) for the development of sport specific LTAD frameworks and to generate debate and discussion surrounding athlete development. In relation to the former, Sport Canada would undergo a systematic process of supporting (i.e. funding) National Sport Organizations to develop sport-specific LTAD frameworks (see Table 3 for an overview of Sport Canada LTAD-related funding). The first sport-specific LTAD frameworks were completed in 2007, with all sports funded by Sport Canada having produced an LTAD framework by early 
Running head: CS4LLT: EPISTEMIC COMMUNITY

2013. With relation to the latter, it is evident that the original resource document had the allure of 'scienciness' (Collins \& Bailey, 2013), but was written in such a way that it could be read and easily understood by just about anybody; a notable departure from Balyi's previously published physiologist, periodization and coach-centric works. As one CS4LLT Member recalled, at the beginning it was really a few guys who wrote a paper...they just glued together a bunch of long-term athlete development studies and made it accessible. Nothing revolutionary but they made it accessible. They spoke about it in the language that people understood (CS4LLT Member \#4 01/30/13).

It is apparent, however, even from the LTAD Expert Group's own account that the resource document produced was admittedly "a basic 'pop science' resource and guide" (Norris, 2010, p. 380), but was viewed as a necessary step

to overcome an obvious inertia to change in the Canadian system, particularly at a time when there was increasing recognition and vocalization of various challenges or negative consequences (i.e., high dropout rates from organized activities and sports, increasing obesity (Norris, 2010, p. 380).

In this manner, the purpose of publishing the original resource document was not to demonstrate scientific truth per se, but rather to generate debate and act as a "'lightening rod' or catalyst to inspire (or even incense) discussion and action" (ibid, p. 380). The apparent 'pop science' nature of the resource document is consistent with Haas's (1992) viewpoint that epistemic communities produce "consensual knowledge, they do not necessarily generate truth, [but rather]...temporally bounded notions of truth" (p. 23). Consequently, the information produced by epistemic communities (such as the CS4LLT) is often provisional in that it is not guesswork nor is it entirely based upon scientific fact; in other words, it is the 'best guess' given limited rationality (Dunlop, 2012; Haas, 1992). For this reason, Alder (1992) goes as far to describe epistemic community's knowledge as imaginary in that there is no way to empirically test their truth claims. Even the CS4LLT openly acknowledges this idea/limitation and went so far as to 
Running head: CS4LLT: EPISTEMIC COMMUNITY

explicitly embedded it within the LTAD framework itself through the adoption of the concept of Kaizen; a Japanese business term commonly associated with continuous improvement or change for the better. It is therefore perhaps more appropriate and accurate to describe the publication of Balyi et al's (2005) generic LTAD framework as the CS4LLT's general consensus of knowledge at the time, rather than any attempt to generate scientific 'truth' per se - a common misconception amongst scholars who have previously critiqued the LTAD framework (e.g., Black \& Holt, 2009; Ford et al., 2011; Lang \& Light, 2010).

The publication of the 2005 resource paper also had significance and for the shaping of government thinking regarding the athlete development process and the emergence and development of LTAD/CS4L. In relation to the former, the publication of the generic framework provided a potential solution to CSP1's identified problem of how to produce athletes in a systematic manner. For Haas (1992), the information produced by an epistemic community "consists of depictions of social or physical process, their interrelation with other processes, and the likely consequences of actions that require application of considerable scientific or technical expertize" (p. 4). Not only did the original resource document offer a clear depiction and interpretation of the cause and effect of the inherent failures of Canadian sport by explicitly identifying its "shortcomings and consequences" (Balyi et al., 2005, p. 17), but it also articulated more nuanced, scientific-like interpretation of the athlete development process not previously recognized by either government or CSP1. Furthermore, the publication of the 2005 resource paper would also be a critical step in Sport Canada's realization that LTAD/CS4L could contribute to other areas beyond high performance sport. From a Sport Canada perspective, "it didn't take long for us to realize that this [LTAD] really was a comprehensive system framework that spoke to much more than developing Olympic athletes" (Senior Sport Canada Official \#21 
Running head: CS4LLT: EPISTEMIC COMMUNITY

02/05/13). From a CS4LLT perspective, "we realized early on in the process as we created LTAD that there was a need to go younger and talk about what happens in those early years" (CS4LLT Member \#15 04/22/13). This realization would, in turn, lead the expert group to intentionally re-label the LTAD generic framework 'Canadian Sport for Life' as a more encompassing and broader term than LTAD.

The 2005 resource document was also significant to the establishment of the CS4LLT as an epistemic community. In particular, the generic LTAD framework provided an explicit articulation of a clearly defined set of shared principles and casual beliefs that would become foundational to the CS4LLT's endeavour. According to Haas (1992), it is these shared and casual beliefs that distinguish epistemic communities from other types of collective organization and provide the necessary foundation for epistemic communities to establish authority claims in order to influence the policy process. The Expert Group's original resource document can therefore be viewed as the culmination of Balyi and colleagues' works throughout the 1990s and essential to establishing the CS4LLT as an epistemic community in that it created a high degree of clarity regarding its overall intent and vision for, and outlined the necessary actions required to, develop Canadian sport.

Since the publication of the original resource document, the CS4LLT have also published a series of 'supplementary' documents. These supplementary documents have elaborated on the specific principles of the framework (e.g., Developing Physical Literacy) and extended its application to targeted groups (e.g., the Female Athlete Perspective, Aboriginal Sport for Life), all of which provided further support for and promotion of the LTAD framework itself and, by extension legitimized the CS4LLT as experts within the athlete development domain. Even more apparent has been the CS4LLT's pragmatic use of these supplementary documents (or more 
Running head: CS4LLT: EPISTEMIC COMMUNITY

accurately the process of creating them) in order to develop its own professional network and extend its own reach beyond the sporting domain. For example, the CS4LLT collaborated with the Canadian Parks and Recreation Association to publish a document entitled Building Enhanced Collaboration between Recreation and Sport (CS4L/CPRA, 2013). Not only did this document outline the role of municipal recreation organizations in sport and physical activity and proposed several strategies to enhance the collaboration between sport and recreation, but more pragmatically the process enabled the CS4LLT to build a direct working relationship with the Canadian Parks and Recreation Association. This partnership working process even led to a Canadian Parks and Recreation Association governing board member to become a CS4LLT member. ${ }^{5}$ Through the slow but steady process of producing the generic framework and its various supplementary documents the CS4LLT was able to further articulate the cause and effect relationships of LTAD framework specifically and the athlete development process more generally, and in doing so, the group was able frame much of the athlete development debate that followed (Dunlop, 2012).

\section{The LTAD Workshop/CS4L Summit}

A second LTAD/CS4L related development that has been central to the CS4LLT's establishment of knowledge/truth claims has been the creation of a national conference. In January 2006, the CS4LLT hosted its first LTAD workshop in Ottawa with over 147 delegates in attendance, comprising largely of sport practitioners and government officials. This workshop has expanded significantly and has been subsequently renamed the Canadian Sport for Life National Summit and continues to be held in Ottawa on an annual basis. The CS4L Summit

\footnotetext{
5 More recently, (August, 2014) the CS4LLT have produced an aboriginal-specific LTAD framework entitled 'Aboriginal Sport for Life: Aboriginal Long Term Participant Development 1.0' through similar partnership/network arrangements. See: http://canadiansportforlife.ca/sites/default/files/resources/AS4L-LTPD

Outline\%20August \%202014_EN.pdf
} 
Running head: CS4LLT: EPISTEMIC COMMUNITY

along with the World Long-Term Athlete Development symposium (held bi-annually) remains the central mechanism through which the CS4LLT and Sport Canada have been able to promote the LTAD framework domestically and internationally and has now become the second largest sport conference in Canada with 508 delegates registered in 2012 (see Figure 1).

\section{$* * *$ Insert figure 1 here $* * *$}

In epistemic community terms, the conference serves as an important common practice amongst the wider CS4L network that helps maintain internal and external interest and solidarity. Haas (1992) states that such practices contribute to epistemic community survival by: provid[ing] members with a valuable institutional structure in which to compare information and find moral support for their sometimes socially and politically marginalized beliefs. They also strengthen the commitments of individuals and inhibit them from subsequently recanting the beliefs share with and reinforced by their follows community members (p. 20).

In particular, it is evident from attending these summits that the program schedule and sessions are designed in such a way that delegate discussions are not about debating the principles and practices of LTAD (although some initial debate occurred within the workshop/summits during its formative years) or whether LTAD should be adopted over other alternative athlete development frameworks/models (see discussion below). Rather, the workshop/summit is designed in such as manner as to provide delegates with the opportunity to develop a greater awareness and understanding of LTAD and its underpinning principles and to discuss how best to implement LTAD by offering examples of LTAD-related best practice. It seems evident, then, that the ultimate intention of this conference and other similar conferences (e.g., the World Long-Term Athlete Development Symposium and the International Physical Literacy Conference) initiated by the CS4LLT has therefore been to embed and institutionalize 
Running head: CS4LLT: EPISTEMIC COMMUNITY

the LTAD framework into the Canadian sporting lexicon as the way of conceptualizing athlete development.

\section{(iii) Influencing the Canadian sport policy renewal process}

As a result of the abovementioned intergovernmental government decisions, CS4LLT's reframing of the athlete development 'problem', and ongoing efforts establish knowledge-claims surrounding athlete development, the leadership team was able to influence the sport policy renewal process that would follow. In order to ensure an effective transition from CSP1 to its successor policy (CSP2), F-P/T Sport Ministers agreed in August 2009 to review the progress of CSP1, determine the interest and merit of a new policy, and undergo the work needed to produce a successor policy (Canadian Heritage, 2012). These three elements and the actions that stemmed from it are collectively referred to as the Canadian Sport Policy Renewal (CSPR) process.

Overseen by the F-P/T Sport Committee, the CSPR process occurred over three-year period (i.e., 2009-2012) and involved extensive consultation between government and the sport community.

\section{LTAD/CS4L's derailment from the CSP renewal process}

One of the more pertinent findings in relation to the CS4LLT and the CSP renewal process was the resistance LTAD/CS4L faced during the political debates that occurred during the later stages of the process. This political resistance would chiefly manifest itself in the debates regarding how the new policy should be fundamentally organized. In particular, two frameworks were put forward during the initial consultation process as fundamental organizing frameworks for the new policy. The first conceptualization was the leadership teams' CS4L Rectangle diagram, depicting LTAD's seven-stage athlete development pathway of sport from playground to podium. The second and alternative framework to CS4L's rectangle was a Venn diagram (also known as the Spheres Model) that was proposed by a select few key individuals - 
Running head: CS4LLT: EPISTEMIC COMMUNITY

namely, but not exclusively, from the province of Québec (see Figure 2 for an overview of these two conceptualizations).

As a result of these two conceptualizations being put forward, a political debate and a false 'either-or' dichotomy was created between the Venn diagram primarily supported by representatives of Québec on the one hand, versus the CS4L Rectangle that had been adopted and endorsed by the rest of Canada on the other. A Sport Canada official reflected on this tension, "It became a highly political issue, with a lot of positioning in and around it...early on it became polarized as opposed to really being able to work through the issues" (Sport Canada Official \#22 01/17/13). The official continued,

I think there was a sense that the model of the three spheres came from a model that has been used in Québec since 1984. I think that there is certainly an argument to be made that because of the way that the writing team is composed and so on and so forth, that really led to a whole sense that a dichotomy existed between, 'We could either use the spheres or we could use the [CS4L] pathway' (Sport Canada Official \#22 01/17/13).

*** Insert figure 2 here***

It is important to note that the Québec representatives were not (and are still not)

necessarily against LTAD/CS4L in principal, in fact, many of LTAD/CS4L's principles such as Fundamental Movement Skills and Physical Literacy and the CS4LLT produced documentation were generally well-received and welcomed by representatives of the province. In support of this viewpoint, a senior Sport Canada official stated,

we had the unique challenge of one of our jurisdictions, Québec, essentially saying that they didn't endorse Canadian Sport for Life. It's not that they were against it but they would not re-endorse it as the sole method. They felt that there were other frameworks that they felt equally comfortable with and were not prepared to put all of the eggs into the Canadian Sport for Life basket (Senior Sport Canada Official \#18 07/22/13).

Similarly,

I think the only province that it was putting a barrier to it was Québec, because they have their own way of doing it, they are so opposed to their associations to have to adopt the 
Running head: CS4LLT: EPISTEMIC COMMUNITY

national model. They are not against it, but they are against it for political reasons, for other reasons (Senior Sport Canada Official \#19 07/26/13).

Nonetheless, it was the view of those representing the province of Québec at the time that it had already addressed its need for systematic approach to athlete development. As a CS4LLT member stated,

Québec had already initiated a planning process...that looked very much like LTAD before LTAD, so Québec could rightfully claim that they already had LTAD which they weren't calling LTAD, before LTAD and so their position formally ever since has been we have our own thing and we're not adopting any pan-Canadian thing because we have our own thing which is their position on just about everything (CS4LLT Member \#13 01/29/13).

In drawing from the above quotations, the political debate that ensued was not necessarily about LTAD's merit and appropriateness as Canada's de facto athlete development framework per se, but rather LTAD/CS4L became the focal topic of a much larger and longstanding political debate regarding Québec and the rest of Canada. The debate would finally culminate with a key governmental representative from Québec explicitly and forcefully denouncing the usage of LTAD/CS4L at a consultation meeting by threatening not to sign-off on the newly developed policy, should the CS4L Rectangle be adopted,

It was only at the consultation process when finally somebody from Québec stood up and said 'If you stick it in there, I won't sign it.' All of a sudden, there was this silence that went across the room. Everyone kind of went, 'We didn't realize this is...' That was one of many that they didn’t realize (CS4LLT Member \#8 01/31/13).

It was the view of many respondents interviewed that the Venn diagram was broader and more inclusive than the CS4L Rectangle. In this manner, and in spite of the CS4LLT's efforts over the past decade, they argued that CS4L's conceptualization of sport had yet to be fully adopted across Canada, and therefore, could not claim to be truly Canadian. Furthermore, and rather ironically, the CS4L Rectangle conceptualization was also limited in that it primarily (although not exclusively) focused on athlete development within the sport domain - hence long-term 
Running head: CS4LLT: EPISTEMIC COMMUNITY

athlete development. As such, it was argued by critics at the time that the CS4L Rectangle did not, for example, meaningfully incorporate broader definitions of sport. A CS4LLT member elaborated on this point,

In this case, the sport policy was not about an athlete pathway. The sport policy this year, this time, sport was being redefined as broader than sport. That's why in the end, just an athlete pathway didn't encompass what they later tried to play it through. They saw it and they worked with it, that said 'it's not meeting the broader consultation is defining as sport (CS4LLT Member \#8 01/31/13).

Adopting a broad conceptualization of sport also had a number of political benefits for government. First, pragmatically it ensured that all provinces and territories would endorse the new policy. Second, a broader definition would enable the governments of Canada and the sport community at large to work closer with other interlinking sectors such as health, education, and recreation. This lack of inter-sector connectivity was considered a limitation of its predecessor, CSP1. Third, and an alternative motive for why the CS4L Rectangle was not identified as the fundamental organizing perspective of the new policy was the recognition that a broader conceptualization would also ensure that successive governments would be able to interpret CSP2 as they deemed appropriate. As one CS4LLT member stated, "I think it's a policy written so that it can be interpreted by successive governments in any way they see fit" (CS4LLT Member \#5 01/29/13). Consequently, it can be argued that the adoption of the Venn diagram over CS4L's rectangle allowed government(s) greater flexibility in making decisions regarding whether or not to invest in LTAD/CS4L in the future.

As a direct consequence of the governmental representative from Québec explicitly denouncing LTAD/CS4L, and the abovementioned political benefits of adopting a broader conceptualization of sport, the drafting committee made the decision to adopt the Venn diagram as the fundamental organizing principle of the new policy; a decision that would effectively 
Running head: CS4LLT: EPISTEMIC COMMUNITY

derail LTAD/CS4L from policy process. This is not to suggest that the leadership team or LTAD/CS4L were dismissed from the renewal process entirely. On the contrary, and in spite of this political resistance, LTAD/CS4L principles were incorporated into the final draft of the new policy. Nonetheless, the political resistance faced during the latter part of the consultation process, along with the political benefits sought by government, resulted in LTAD/CS4L having a far more reduced prominence within the final draft of new policy.

\section{Conclusion}

This investigation examined how the CS4LLT as newly emergent organizational form has been able to influence the Canadian sport policy and governance process. The case of the CS4LLT and its creation, promotion and dissemination of the LTAD framework illustrates how the discursive interventions of an epistemic community can reframe and establish scientific-like truth claims surrounding policy-relevant issues (such as athlete development) in order to gain influence over the policy process. Over the past decade, the leadership team has used its technical knowledge to socially (re)construct and insert its own interpretation of the athlete development process (namely the LTAD framework) that would, in time, be adopted and legitimized by government (via Sport Canada) and many sport organizations across Canada as the de facto approach to athlete development. The adoption and legitimization of LTAD/CS4L by Sport Canada, would, in turn, enable the CS4LLT to adopt an increasingly influential role within Canadian sport, and even in spite of political resistance, directly and indirectly influence the Canadian sport policy process.

This paper has focused primarily on how the CS4LLT has been able to influence the Canadian sport policy process, however, evidence collected as part of the study also suggested that government (i.e. Sport Canada) has adopted the LTAD framework as a conceptual/ 
Running head: CS4LLT: EPISTEMIC COMMUNITY

organizing framework in order to clarify sport organizations' roles and responsibilities within the general athlete development process. In this manner, Sport Canada and other stakeholders viewed the LTAD framework as a potential 'solution' to solving one of Canada's longstanding 'problem' of system fragmentation (Barnes et al., 2007). Furthermore, despite being perceived as a non-governmental organizational-like entity, it is evident from the funding dependencies between the CS4LLT and Sport Canada (see Figure 1) and the leadership teams' own accounts that the leadership team (and by extension the LTAD framework) would not have emerged and developed without continued governmental support. Thus, despite the CS4LLT claiming relative autonomy and independence from government, the knowledge-based professional network was and still continued to be enabled and constrained from and working towards objectives that have been determined by the state. This is perhaps most evident from the CS4LLT's broadening of focus from solely high performance sport to an increasing emphasis on the broader athlete development pathway.

More cynically, then, Sport Canada's decision to require sport organizations to adopt the framework specifically and Sport Canada's decision to support the CS4LLT more generally can be viewed as an attempt by government to gain greater control over Canadian sport in order to achieve its own objectives. From this perspective, the adoption of LTAD/CS4L can be viewed as yet another accountability mechanism and instrument of 'governmentality' that has been adopted by Sport Canada in an attempt to modernize or rationalize Canadian sport (Green \& Houlihan, 2006; Havaris \& Danylchuk, 2007; Thibault \& Harvey, 2013; Whitson \& Macintosh, 1990). Furthermore, the blurred-boundary between the CS4LLT and Sport Canada, raises much larger questions beyond the scope of this investigation regarding the leadership teams' role within the broader governance process. For Cross (2013), "it is clear that epistemic communities not only 
Running head: CS4LLT: EPISTEMIC COMMUNITY

seek to persuade states, but also a variety of non-state actors. They are not only underpinning specific government policies, but also shaping governance process more broadly" (p. 139). If the CS4LLT are effectively working towards objectives that determined by the state, what mechanisms are there to ensure appropriate 'good governance' (i.e., transparency, accountability etc.)?

In turning to the specific contributions of the paper, first and foremost, the investigation highlights the role and importance of epistemic communities as potentially influential organizational forms that are able to navigate complex organizational landscapes in order to influence the sport policy and governance process. The epistemic community approach therefore provides a useful alternative perspective to the other now 'well-travelled' meso-level theoretical approaches such as advocacy coalitions (e.g., Green, 2004; Green \& Houlihan, 2005), multiplestreams (e.g., Green \& Houlihan, 2006), lesson drawing and policy transfer (e.g., Green, 2007), and path-dependency (e.g., Green \& Collins, 2008). In particular, the epistemic community approach in general and the case of the CS4LLT specifically highlights the ability of non-state actors (i.e., academics/practitioners) to use knowledge to gain power of and over the policy process, even in the absence of direct and formal mechanisms that enables them to do so.

Second, this study responds to Thibault and Harvey's (2013) call to examine contemporary developments within the Canadian sport landscape, specifically in relation to governmental involvement in sport. The investigation not only examined the evolution of the CS4LLT over the past decade, but in doing so, also highlighted a number of tensions, both within and beyond the sporting organizational landscape as well as between sport and federal government, that have arisen as a result of the emergence and development of the leadership team. It is apparent, then, that new organizational forms like epistemic communities are able to 
Running head: CS4LLT: EPISTEMIC COMMUNITY

navigate difficult and challenging policy spaces, however, these attempts can produce new and often unintended political consequences (Sam, 2009) that may cause greater inter-organizational tensions and dilemmas (evidenced here by political debates that occurred as a result of the CS4LLT inserting LTAD into the renewal process) rather than reducing them. Third, this investigation also contributes to the more specific debates surrounding athlete development models and the LTAD framework in particular by providing a socio-political explanation for how and why the LTAD framework, as a comparatively under-researched framework, has been adopted by federal government and the sporting community as the de facto organizing framework for athlete development within Canada. To offer some potential avenues for future research, in relation to more theoretically focused directions of research, the existence of similar sport-based epistemic communities within other countries and sporting contexts still remains open to empirical debate with more research required to understand the nature and extent of these communities as potentially influential organizational approaches to organizing and managing sport. With regards to the CS4LLT specifically, it is evident that more research is still required to examine the CS4LLT's role as a newly emergent organizational form now operating within Canadian sport. In particular, there is a need to understand further the nature of the relationship between the leadership team and government and the influence of the CS4LLT and the LTAD/CS4L on sport organizations. 
Running head: CS4LLT: EPISTEMIC COMMUNITY

\section{References}

Adler, E. (1992). The emergence of cooperation: national epistemic communities and the international evolution of the idea of nuclear arms control. International Organization, 46(1), 101-145. doi:10.1017/S0020818300001466

Andrew, D., Pedersen, P., \& McEvoy, C. (2011). Research methods and design in sport management. Champaign, IL: Human Kinetics.

Antoniades, A. (2003). Epistemic Communities, Epistemes and the Construction of (World) Politics. Global Society, 17(1), 21-38. doi:10.1080/0953732032000053980

Balyi, I., Way, R., \& Higgs, C. (2014). Long Term Athlete Development. Champaign, IL: Human Kinetics.

Balyi, I., Way, R., Norris, S., Cardinal, C., \& Higgs, C. (2005). Canadian sport for life: Longterm athlete development resource paper. Vancouver, BC: Canadian Sport Centres.

Banack, H. R., Bloom, G. A., \& Falcão, W. R. (2012). Promoting Long-Term Athlete Development in Cross Country Skiing Through Competency-Based Coach Education: A Qualitative Study. International Journal of Sports Science and Coaching, 7(2), 301-316.

Barnes, M., Cousens, L., \& MacLean, J. (2007). From silos to synergies: a network perspective of the Canadian sport system. International Journal of Sport Management and Marketing, 2(5), 555-571. doi: 10.1504/IJSMM.2007.013967

Black, D., \& Holt, N. (2009). Athlete Development in Ski Racing: Perceptions of Coaches and Parents. International Journal of Sports Science and Coaching, 4(2), 245-260.

Brisson, T. (2004). Targets for athlete performance and the sport system. Draft report submitted to the Interprovincial Sport and Recreation Council in spport of the FederalProvincial/Territorial Enhanced Excellence Priorities for Collaborative Action 2002-2005. 
Running head: CS4LLT: EPISTEMIC COMMUNITY

Canadian Heritage. (2002a). Canadian sport policy 2002-2012. Ottawa: Author.

Canadian Heritage. (2002b) Federal-Provincial/Territorial Priorities for Collaborative Action (F-P/TPCA) 2002-2005. Ottawa: Author.

Canadian Heritage. (2009). Long-Term Athlete Development Strategic Framework for 20092014. Ottawa: Author.

Canadian Heritage. (2012). Canadian sport policy 2012. Ottawa: Author. Retrieved from: http://sirc.ca/CSPRenewal/documents/CSP2012_EN.pdf. [Accessed 01/31/13]

Collins, D., \& Bailey, R. (2013). 'Scienciness' and the allure of second-hand strategy in talent identification and development. International Journal of Sport Policy and Politics, 5(2), 183-191. doi: 10.1080/19406940.2012.656682

Comeau, G. (2013). The evolution of Canadian sport policy. International Journal of Sport Policy and Politics, 5(1), 73-93. doi:10.1080/19406940.2012.694368

Cross, M. K. (2013). Rethinking epistemic communities twenty years later. Review of International Studies, 39(2), 137-160. doi: 10.1017/S0260210512000034

De Bosscher, V., De Knop, P., Van Bottenburg, M., \& Shibli, S. (2006). A conceptual framework for analyzing sports policy factors leading to international sporting success. European Sport Management Quarterly, 6, 185-215. doi:10.1080/16184740600955087

Dowling, M., \& Smith, J. (2016). The instititutional work of Own the Podium in developing high performance sport in Canada. Journal of Sport Management 30(4), http://dx.doi.org/10.1123/jsm.2014-0290 
Running head: CS4LLT: EPISTEMIC COMMUNITY

Drake, W., \& Nicolaidis, K. (1992). Ideas, Interests, and Institutionalization: “Trade in Services" and the Uruguay Round. International Organization, 46(1), 37-100. Retrieved from http://www.jstor.org/stable/2706952

Duffy, P., Balyi, I., Aboud, S., Gregg, R. (2003). Building pathways in Irish sport: towards a plan for the sporting health and well-being of the nation. Limerick, Ireland: National Coaching and Training Centre.

Dunlop, C. (2012). Chapter 19 : Epistemic Communities. In E. Araral, S. Fritzen, M. Howlett, M. Ramesh, \& W. Xun (Eds.), Handbook of Public Policy (pp. 229-243). Routledge.

Eisenhardt, K. M., \& Graebner, M. E. (2007). Theory building from cases: Opportunities and challenges. Academy of Management Journal, 50(1), 25-32.

Ford, P., Croix, M. D. S., Lloyd, R., Meyers, R., Moosavi, M., Oliver, J., \& Williams, C. (2011). The long-term athlete development model: Physiological evidence and application. Journal of Sport Sciences, 29(4), 389-402.

Green, M. (2004). Power, policy, and political priorities: Elite sport development in Canada and the United Kingdom. International Journal for the Sociology of Sport, 21(4), 376-396.

Green, M. \& Collins, S. (2008). Policy, politics and path dependency: sport development in Australia and Finland, Sport Management Review, 11(3), 225-251, doi:10.1016/S14413523(08)70111-6

Green, M., \& Houlihan, B. (2005). Elite Sport Development Policy Learning and Political Priorities. London: Routledge.

Green, M., \& Houlihan, B. (2006). Governmentality, modernization, and the "disciplining" of national sporting organizations: Athletics in Australia and the United Kingdom. Sociology of Sport Journal, 23, 47-71. 
Running head: CS4LLT: EPISTEMIC COMMUNITY

Green, M. \& Houlihan, B. (2006). The changing status of school sport and physical education: explaining policy change. Sport, Education and Society, 11(1), 73-92. doi:10.1080/13573320500453495

Grix, J., \& Carmichael, F. (2012). Why do governments invest in elite sport? A polemic. International Journal of Sport Policy and Politics, 4(1), 73-90.

doi: $10.1080 / 19406940.2011 .627358$

Haas, P. (1989). Do regimes matter? Epistemic communities and Mediterranean pollution control. International Organization, 43(3), 377. doi: 10.1017/S0020818300032975

Haas, P. (1992). Introduction: epistemic communities and international policy coordination. International Organization, 46(1), 1-35. Retrieved from http://www.jstor.org/stable/2706951

Haas, P., \& Adler, E. (Ed.). (1992). Knowledge, Power, and International Policy Coordination [Special Issue]. International Organization, 46,1-390.

Havaris, E., \& Danylchuk, K. (2007). An assessment of sport Canada's sport funding and accountability framework, 1995-2004. European Sport Management Quarterly, 7(1), 31 53.

Houlihan, B. (2005). Public sector sport policy: Developing a framework for analysis. International Review for the Sociology of Sport. 40(2), 163-185. doi: $10.1177 / 1012690205057193$

Houlihan, B., Bloyce, D., \& Smith, A. (2009). Developing the research agenda in sport policy. International Journal of Sport Policy and Politics, 1(1), 1-12. doi:10.1080/19406940802681186 
Running head: CS4LLT: EPISTEMIC COMMUNITY

Ikenberry, G. J. (1992). A world economy restored: expert consensus and the Anglo-American postwar settlement. International Organization, 46(1), 289. http://doi.org/10.1017/S002081830000151X

Lang, M., \& Light, R. (2010). Interpreting and Implementing the Long-Term Athlete Development Model: English Swimming Coaches' Views on the (Swimming) LTAD in Practice. International Journal of Sports Science and Coaching, 5(3), 389-402.

Mayan, M. (2009). Essentials of qualitative inquiry. Walnut Creek, CA: Left Coast Press.

Miles, M., Huberman, M., \& Salañda, J. (2013). Qualitative Data Analysis: A Methods Sourcebook. ( $3^{\text {rd }}$ Edn). London: Sage.

Misener, L., \& Misener, L. (2015). Call for Papers for the Special Issue: Blurring Sector Boundaries \& New Organizational Forms. Journal of Sport Management. Retrieved from: journals.humankinetics.com/jsm-extras/

Norris, S. (2010). Long-term athlete development Canada: attempting system change and multiagency cooperation, Current Sports Medicine Reports, 9(6), 379-382.

Own the Podium. (n.d.a). Summer historical comparison. Retrieved from: http://www.ownthepodium.org/Funding/Summer-Historical-Comparison.aspx [Accessed 11/07/16].

Patton, M. Q. (2002) Qualitative research and evaluation methods. Thousand Oaks, CA: Sage.

Peterson, M. J. (1992). Whalers, Cetologists, Environmentalists, and the International Management of Whaling. International Organization, 46(1), 147-186. Retrieved from http://www.jstor.org/stable/2706954

Sam, M. (2009). The public management of sport: wicked problems, challenges and dilemmas. Pubic Management Review, 11(4), 499-514. doi: 10.1080/14719030902989565 
Running head: CS4LLT: EPISTEMIC COMMUNITY

Sandal, N. (2011). Religious actors as epistemic communities in conflict transformation: the cases of South Africa and Northern Ireland. Review of International Studies, 37(3), 929949. doi: $10.1017 / \mathrm{S} 0260210510001592$

Sebenius, J. (1992). Challenging conventional explanations of interntional cooperation: negotiation analysis and the case of epistemic communities. International Organization, 46(1), 323-365. Retrieved from http://www.jstor.org/stable/2706959

Stafford, I. (2005). Coaching for Long-Term Athlete Development. Leeds: Coachwise Business Solutions/ UKSport

Thibault, L., \& Harvey, J. (Eds.). (2013). Sport Policy in Canada. Ottawa: Ottawa University Press.

Toke, D. (1999). Epistemic communities and environmental groups. Politics, 19(2), 97-102. doi: $10.1111 / 1467-9256.00091$

Yin, R. K. (2013). Case study research: design and methods. $\left(5^{\text {th }}\right.$ ed.). Thousand Oaks, CA: Sage. 
Running head: CS4LLT: EPISTEMIC COMMUNITY

Table 1: Canadian Sport for Life Leadership Team

\begin{tabular}{lllll}
\hline Member & Year & Degree & Organization & Background \\
\hline Richard Way & 2004 & MBA & CSI Pacific & Consultant (Citius) \\
Istvan Balyi & 2004 & MSc & NCI Victoria & Consultant (T\&P ltd) \\
Colin Higgs & 2004 & PhD & Consultant & Consultant \\
Charles Cardinal & 2004 & MSc & Consultant & Consultant \\
Stephen Norris & 2004 & PhD & Winsport & Winsport Vice President \\
Vicki Harber & 2009 & PhD & Alberta University & Physiologist \\
Mark Vulliamy & 2011 & & Consultant & Recreation consultant \\
David Legg & 2011 & PhD & M.Royal University & Paralympic sport \\
James Mandigo & 2011 & PhD & Brock University & Education consultant \\
Jim Groves & 2011 & & Consultant & Communications \\
André Lachance & 2011 & & Ottawa University & Baseball Canada \\
Paul Jurbala & 2011 & MSc & Consultant & Consultant \\
Carolyn Trono & 2011 & & Rowing Canada & Coach Education \\
Christian Hrab & 2010 & & Sporting DNA & NSO Director \\
Debra Gassewitz & 2011 & & SIRC & President \& CEO \\
Danielle Bell & 2011 & & CSI Pacific & Citius Administration \\
Thom Brennan & 2011 & & CSI Pacific & Citius Administration \\
\hline Source: & & &
\end{tabular}

Source: http://www.cs4l.ca; CS4LLT personal communications 
Running head: CS4LLT: EPISTEMIC COMMUNITY

Table 2: Overview of Data Sources

\begin{tabular}{l} 
Primary Sources \\
Interview Transcripts: \\
a. Any current member of the CS4L Leadership Team (17 transcripts) \\
b. Sport Canada officials who have in-depth knowledge of the CS4LLT and \\
its emergence and development ( 5 transcripts) \\
\hline Supplementary Sources \\
\hline Documents: \\
a. \\
Any CS4LLT produced documentation since 2004. This includes blog \\
posts, presentations, discussion papers, workbooks, booklets and position \\
statements (38 documents) \\
b. Any F-PT government/Sport Canada produced documentation pertaining to \\
CS4L. This includes ministerial meeting minutes, strategic frameworks and \\
unpublished internal documentation (7 documents). \\
c. Any documentation produced as part of the Canadian sport policy process \\
since 2000 (i.e., CSP1 2002-2012, the CSP renewal process, and CSP2 \\
2012-2022). This includes consultation documents, summary reports, draft \\
policies, and actions plans (24 documents) \\
Additional Sources: \\
d. Research notes from three CS4L annual conferences, two world \\
symposiums, three CS4L mini-summits, one International Physical \\
Literacy conference. \\
e. Annual summit conference attendance data of the CS4L annual conference \\
since its inauguration (2006-present).
\end{tabular}


Running head: CS4LLT: EPISTEMIC COMMUNITY

Table 3: Sport Canada LTAD/CS4L Funding Since 2008-09*/**

\begin{tabular}{llll}
\hline Fiscal Year & Leadership Team & $\begin{array}{l}\text { National Sport } \\
\text { Organizations }\end{array}$ & Total \\
\hline $2008-09$ & $\$ 475,000$ & $\$ 910,000$ & $\$ 1,385,000$ \\
$2009-10$ & $\$ 482,000$ & $\$ 865,000$ & $\$ 1,347,000$ \\
$2010-11$ & $\$ 506,000$ & $\$ 782,000$ & $\$ 1,288,000$ \\
$2011-12$ & $\$ 500,000$ & $\$ 1,008,785$ & $\$ 1,508,785$ \\
$2012-13$ & $\$ 500,000$ & $\$ 1,028,939$ & $\$ 1,347,939$ \\
$2013-14$ (to date) & $\$ 566,000$ & $\$ 383,500$ & $\$ 949,500$ \\
& & & $\$ 8,007,224$ \\
\hline
\end{tabular}

Source: Sport Canada (n.d.)

* Investment figures were not attainable for the 2005-2008 periods. Nonetheless, funding figures would have been similar to the above during the 2005-06, 2006-07 and 2007-08 periods. The initial 2004-05 funding by Sport Canada to the then LTAD Expert Group would have been substantially smaller than above.

** all figures are in Canadian dollars $(\$ C A D)$ 
Running head: CS4LLT: EPISTEMIC COMMUNITY

Figure 1: CS4L Workshop/Summit Total Attendance (2006-2014)

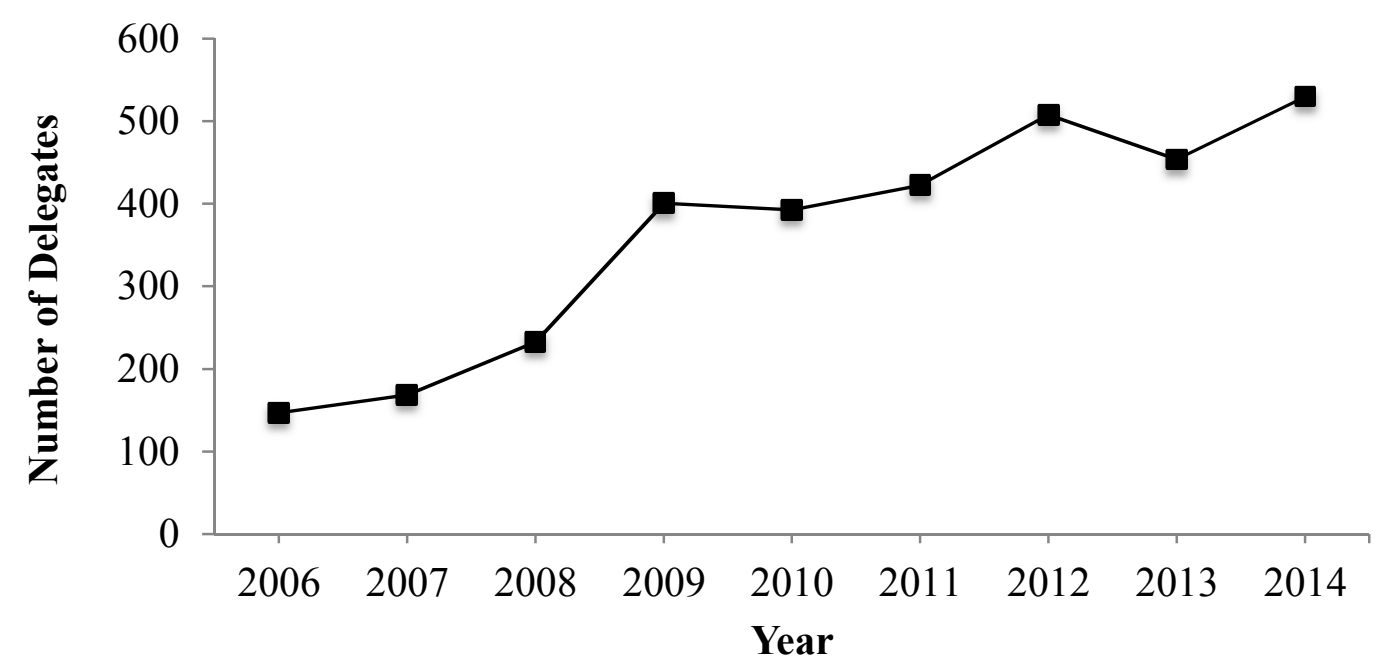


Running head: CS4LLT: EPISTEMIC COMMUNITY

Figure 2: CS4L Rectangle and the Venn (Sphere) Diagram
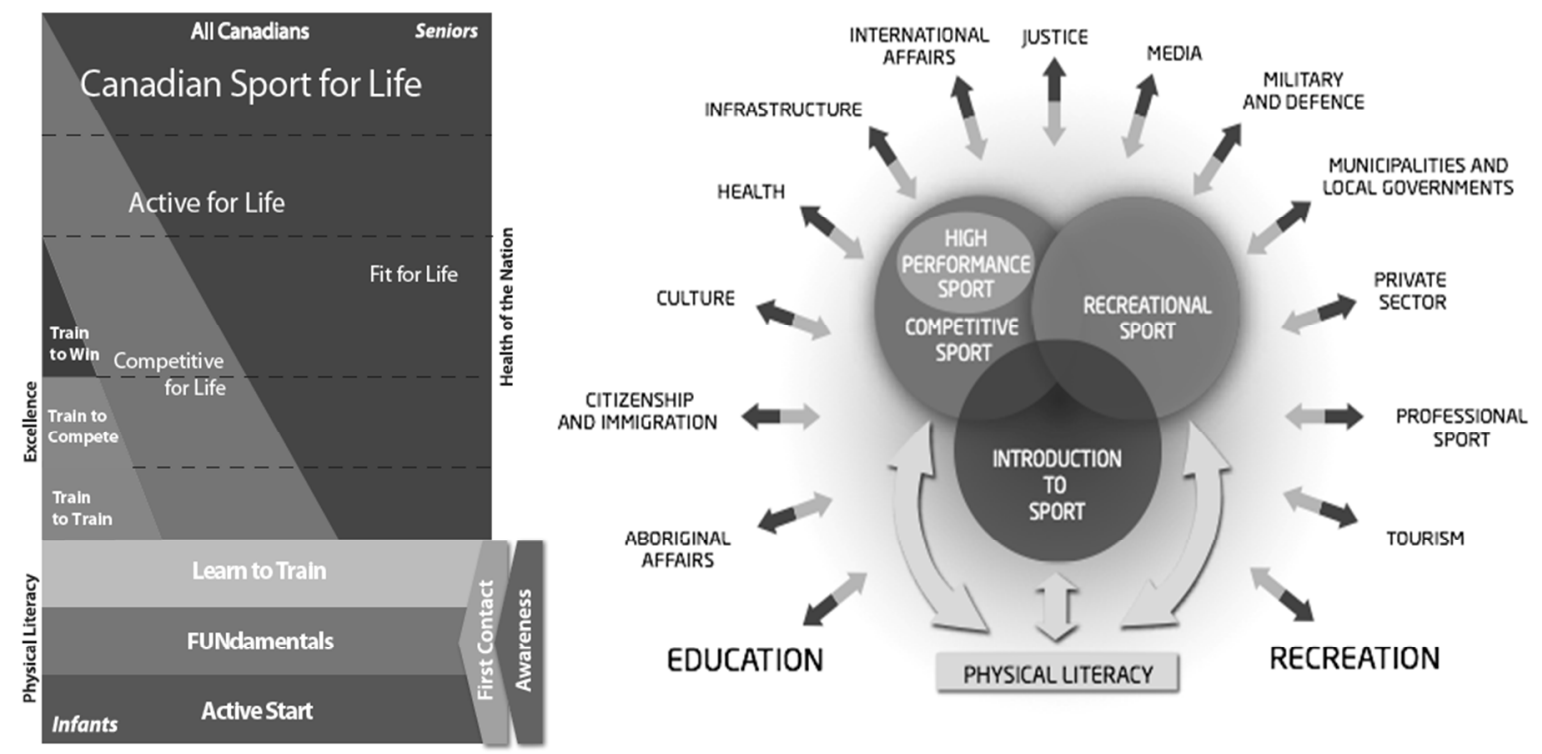

Source: CS4L (n.d.); Canadian Heritage (2012) 
Reviewer(s)' Comments to Author:

Reviewer: 1

This is a very good paper that will make a valuable contribution to the existing literature around sport policy in Canada. It utilizes a well-established framework and with good effect. The analysis is clear and so is paper's conclusion - that some organisations, because of how well they are connected and resourced, can have a substantial influence on public policy. By extension, the manuscript fits well within the JSM special issue's theme of 'blurring boundaries'. To this end, I think the footnote on p.2 (where CS4LLT describe themselves as the 'un-organization') is quite telling and should probably be incorporated into the text.

We incorporated the footnote 'un-organization' reference into the introduction of the manuscript. More specifically we included the following sentence to the section:

"This non-formalized approach is encapsulated in the leadership teams' decision to describe themselves as an 'un-organization'; a term that, according to select members of the leadership team at least, reflected the absence of bureaucratic structures that typify most sports organizations and its relative autonomy and independence from federal government."

Major:

Some recent works with direct contextual relevance to the themes described in the manuscript, including Sport Canada's network challenges and issues, should be integrated into the final text:.

Barnes, M., Cousens, L., \& MacLean, J. (2007). From silos to synergies: a network perspective of the Canadian sport system. International journal of sport management and marketing, 2(5), 555571.

Comeau, G. S. (2012). The evolution of Canadian sport policy. International Journal of Sport Policy and Politics. http://dx.doi.org/10.1080/19406940.2012.694368

Comeau, G. S., \& Church, A. G. (2010). A Comparative Analysis of Women's Sport Advocacy Groups in Canada and the United States. Journal of Sport \& Social Issues, 34(4), 457-474.

Sam, M. P. (2011). Building legitimacy at Sport Canada: pitfalls of public value creation? International Review of Administrative Sciences, 77(4), 757-778.

Sam, M. P. (2009). The public management of sport: Wicked problems, challenges and dilemmas. Public Management Review, 11(4), 499-513.

Thank you for directing our attention to the above articles, we re-read them and where appropriate incorporated them into the manuscript. Reference to these articles can now be found in the following sections of the manuscript:

Page 1

Within Canada, for example, the adoption of the LTAD framework by government occurred, in part, to attempt to respond to and realize the excellence and participation goals of the Canadian Sport Policy 1 (CSP1; 2002-2012), Canada's first national sport policy with bi-lateral agreements between the Federal and Provincial/Territorial (F-P/T) Governments of Canada, and its successor policy, Canadian Sport Policy 2 (CSP2; 2012-2022) (Thibault \& Harvey, 2013; see also Comeau, 2013 for a specific discussion on the evolution of Canadian sport policy). 
Page 6

This study consequently makes the following threefold contributions to the sport management/policy literature. First, we extend recent work that has sought to theorize the meso-level sport policy process (e.g., Comeau, 2013; Green \& Houlihan, 2005; Houlihan, 2005; Houlihan, Bloyce, \& Smith, 2009) by offering the epistemic communities approach as a useful alternative theoretical approach to understand and explain sport policy change.

Page 15

Not only has Canadian sport historically been characterized as a highly fragmented pluralist network (Barnes et al., 2007; Comeau, 2013), but CSP1 (2002-2012) emerged, in part, to attempt to 'deal' with ongoing broader tensions regarding the role of federalprovincial/territorial governments' in sport and sport organizations and the ongoing debate regarding whether or not Canada should continue to prioritize high performance sport over other social objectives (Green \& Houlihan, 2005; Thibault \& Harvey, 2013).

Page 30

In this manner, Sport Canada and other stakeholders viewed the LTAD framework as a potential 'solution' to solving one of Canada's longstanding 'problem' of system fragmentation (Barnes et al., 2007). Furthermore, despite being perceived as a nongovernmental organizational-like entity, it is evident from the funding dependencies between the CS4LLT and Sport Canada (see Figure 1) and the leadership teams' own accounts that the leadership team (and by extension the LTAD framework) would not have emerged and developed without continued governmental support.

Page 32

The investigation not only examined the evolution of the CS4LLT over the past decade, but in doing so, also highlighted a number of tensions, both within and beyond the sporting organizational landscape as well as between sport and federal government, that have arisen as a result of the emergence and development of the leadership team. It is apparent, then, that new organizational forms like epistemic communities are able to navigate difficult and challenging policy spaces, however, these attempts can produce new and often unintended political consequences (Sam, 2009) that may cause greater inter-organizational tensions and dilemmas (evidenced here by political debates that occurred as a result of the CS4LLT inserting LTAD into the renewal process) rather than reducing them

Minor edits:

\section{P. 2, line8: leadership team 'offers'}

Adjustment made

p. 6: What is the difference between the first and fourth ways in which epistemic communities can help decision-makers. The first is that they can clarify the boundaries around a problem and the fourth is that they can frame or reframe a problem.

We cannot of course speak for Haas, but we would suggest that these distinctions are not clear. Our interpretation of Haas's distinction here is that the first (clarifying boundaries) is about the 
identification of the causes and consequences of (pre-existing) problems and the fourth more about how such problems as be framed for collective (future) debate. In this sense the LTAD framework identifies the shortcomings and consequences of the Canadian sport system (first) and the production of the LTAD framework can be viewed as an attempt to reframe athlete development for debate (fourth).

p. 13, line 8: "The decision made by F-P/T Ministers...." This sentence needs to be tightened.

Sentence has been reconsidered and restructured

p. 19, 1st paragraph: “...LTAD should be adopted over other alternative athlete development frameworks/models." Raises the question for the reader: what other models? But since you go on to describe one in detail later on, I simply suggest you put in brackets "(see discussion below)".

Adjustment made

p. 22, 4 lines from the bottom: delete 'pseudo-political debate' as the debate appears to be firmly political, as described subsequently.

Adjustment made

p. 26, 2nd line of 2nd paragraph: Delete 'this'. In the same sentence: should it not be 'expertise' as it is used here as a noun? I think there is another instance of this earlier on - please check.

Adjustments made throughout the manuscript

p. 27: replace modernization with modernize.

Adjustment made

p. 28, line 5-9: I would suggest the authors acknowledge existing works that use the concept of epistemic communities (particularly the works of Houlihan, Green and Houlihan, etc.). This should be done earlier on in the theory section. In the conclusion, there can then be some comment on the utility of the concept in other contexts.

The following line has been added to the theory section:

"Furthermore, it is also apparent that epistemic communities have received little attention within sport management/policy scholarship (for partial treatments see Green \& Houlihan, 2005; Houlihan, 1999; 2005)."

The following paragraph also highlights the contribution of the paper in relation to existing meso-level perspectives (which include the works of Green and Houlihan):

"The epistemic community approach therefore provides a useful alternative perspective to the other now 'well-travelled' meso-level theoretical approaches such as advocacy coalitions (Green, 2004; Green \& Houlihan, 2005; Phillpots, 2013), multiple-streams (Green \& Houlihan, 2006), lesson drawing and policy transfer (Green, 2007), and path-dependency (Green \& Collins, 2008). In particular, the epistemic community approach in general and the case of the CS4LLT specifically highlights the ability of non-state actors (i.e. academics/practitioners) to use knowledge to gain power of and over the policy process, even in the absence of direct and formal mechanisms that enables them to do so." 
p. 28, last paragraph: 'It is only through such carefully designed ...testing that the LTAD...can be fully understood'. This seems to undermine the merits of the manuscript and the view of such quasi-scientific models as political instruments.

The authors agree entirely with this comment and it appropriately resonates with the arguments of Collins \& Bailey and the 'scienciness' of athlete development models

Reviewer: 2.

The emphasis on the technical aspect of athlete development has played a central focus of not only Canadian sport policy but for many nations for many years however there has been very little consideration of this role in the management literature, as such the topic of this manuscript is long overdue and will be of interest not only domestically but internationally as well. Unfortunately, as currently written there are too many concerns for this manuscript to make a valuable contribution to the academic literature. In particular, there are two major areas of concern that I will focus my attention on that would need to be significantly developed before this manuscript might be considered for publication in the Journal of Sport Management. The first concern relates to the conceptual framework and the epistemic policy community approach and the second concern relates to methodology. Both of these are under developed and lead the reader to wonder about the scholarly contribution and reliability and validity of this study. Perhaps the author chose to focus more on providing findings, which represent a significant portion of the manuscript - but in so doing it has compromised the quality of the manuscript. I provide more substantive comments below:

Thank for these comments. To response to the reviewers comments we have focused our revisions on the two major areas identified by the reviewer (i.e. the theoretical background and the methods section).

\section{Conceptual Framework - Epistemic Policy Community}

Epistemic Policy Community is a theoretical framework developed to understand policy development and change. Although the author identifies the 'founder' of this framework - Peter Haas, there is very little development or consideration of this framework - the conceptual underpinnings, nor how it has been applied - initially at the international level and more recently in domestic issues such as environmental policy, defense policy, and sport policy. This section is just too brief for the reader to get a sense in how this framework actually "framed" the study. As such it is not clear whether you have grasped the arguments of this theoretical framework and the type of research that has benefited from its development. This development is important if we are to fully comprehend how this framework will help us understand how the new ideas and knowledge about athlete development and the problems of athletic performance at international events - i.e., the cause-effect relationship between the LTAD and the knowledge the "coaching experts" bring to shaping the high performance policy domain in Canada and perhaps other nations. As a starting point, more than Haas 1992 should be sourced - although a critical piece the development of a conceptual or theoretical framework (it is not clear which approach - and it is important to clarify - the author is using) requires a deeper consideration of the literature and the arguments developed and their meaningfulness for the current topic. We need to know more about the role of members in an epistemic community and how their similar beliefs about cause and effect and methodologies for validating knowledge shape their perspectives. Of particular relevance and what clearly defines an epistemic community as compared to an advocacy coalition for example is its authoritative claim to knowledge - and this knowledge is agreed upon. And so, 
in summary, there needs to be considerably more attention played to this section - fully describing the theory developed by Haas (and Adler), exploring relevant empirical work that has applied the theory, and consider the sport policy research that has explored epistemic communities.

A fuller discussion of the epistemic communities (EC) approach is primarily limited by the word count/journal spacing. Nonetheless, a number of changes were made to the manuscript in order to respond to the reviewers' comments regarding the theoretical background section. These include:

A paragraph was added to the epistemic communities section ( $2^{\text {nd }}$ paragraph). In doing so we:

- Outline the various empirical contexts in which EC's have been explored in recent years.

- Cite a number of additional authors/works that have used the EC/Haas's approach (not withstanding Dunlop's general criticism of a lack of theoretical development of the EC approach more generally)**

- Acknowledge the lack of EC analysis within the sport management literature (a contribution of the submission which we have also attempted to articulate more clearly in the last paragraph of the introduction section and again in the conclusion).

** On this point, the authors also revised the manuscript for the usage of the terminology 'framework'. Although Haas uses such terminology, in the authors' view at least, Haas's original concept has not been elaborated on enough in order to label it a 'framework' per se, as such we adopt the term perspective or approach as more appropriate labels to describe the works within the EC tradition.

The last paragraph of the section was also reworked considerably to reflect further how the EC's approach is particularly beneficial in explaining how the CS4LLT was able to influence the Canadian sport policy process (i.e. the RQ).

\section{Methodology}

A similar lack of detail is evident in this section. The authors need to fully explain the design, the data collection methods, the sampling, the data collection procedures, criteria of validity and reliability (or trustworthiness). It is not enough to state "the analysis below draws upon empirical data collected from a much larger investigation ..." (is there a reference, is this larger study published? If not, it is merely a footnote. The author needs to develop the design of the study that is currently being presented - is it a case study? Data collection procedures - most interviews conducted in $\mathbf{5}$ days? How many interviews conducted during this time? How many conducted in the expanded time frame Jan - September? Were there any follow up interviews? More detail is needed regarding sampling of all sources - interviews, documents, and observations. How was the data analyzed? What approaches/techniques were adopted to enhance the trustworthiness of the study? As currently presented it is difficulty to establish the credibility of the findings. The authors should consult other published empirical papers in the Journal of Sport Management or indeed any sport management or management related journal to identify the specifics and detail necessary. You identify some participants by their real name - was consent given to do this?

As per the reviewers' suggestions, the authors read similar qualitative case study approaches that were recently published in JSM (e.g., Edwards \& Washington, 2016; O'Boyle \& Shilbury, 2016).

A number of changes were made to the manuscript in order to respond to the reviewers' comments regarding the methodology section. These include: 
- A paragraph/section was added to the methodology section outlining the case study approach adopted for the study. This paragraph includes a rationale and justification for the case study approach adopted.

- Adjusted the title of the paper in order to fully reflect the case study approach of the study we also felt this provided a little more clarity and focus to the study more generally.

- The link and discussion to the larger unpublished doctoral investigation in which the data is drawn from is now footnoted as per the reviewers' suggestion. We also provided more detail of the aims of the larger dissertation project and clarified that the doctoral study was unpublished.

- Sub-titles were also added to the section to provide some structure and clarity to the methods section as a whole.

- Sampling - we provided further details of how interview participants were selected and sampled, namely on the basis of their in-depth knowledge of the evolution of CS4LLT and the adoption of LTAD by government we also provide a justification for this.

- Link to the above, we also added a sentence in the first paragraph that acknowledges our awareness of the CS4LLT (sample) bias and a justification for why the leadership team and Sport Canada official were nonetheless the best source of information to answer our RQ.

- More details were added regarding the specific locations of where the interviews took place (and how many took place where and when) and a rationale for why the summit was deemed an appropriate location is now also provided.

- To clarify the data sources collected and how they were used by the researchers we added a table (Table 2: sources of data) to outline the exact data that was collected for purposes of the study.

- Anonymising participants - we adjusted the second paragraph of the sampling and procedure section to acknowledge that we do partly anonymise participants by generic job titles.

- More details were added to outline the number of elements that were incorporated into the study to ensure methodological rigour, namely member checking of transcripts and triangulation to verify primary interview data.

- Data analysis - more details were added to the data analysis section to explain clearly the analystical process that was undertaken, we also provide specific examples of codes and explain exactly how Haas's EC approach was used to help organise and make sense of the data.

The above areas of weakness detract from the detailed description in the Results \& Discussion (which should be re-titled "Findings"). There are 17 pages of findings - which might need a little refocusing as a result of developing the theoretical framework. In addition, the presentation of findings needs some tidying up. For example on page 9 the middle paragraph - is this data? From where? Interviews? Observations? This happens in several areas - claims are made and it is not clear - it comes across as unsubstantiated statements from the author with the occasional supporting reference from Haas 1992 which is seemingly inserted to provide some type of "interpretation" of the data. What the author needs to do is to explain what it is there are hoping to describe - is it the chronological development of the epistemic community? Then provide the analysis and perhaps engage in interpretation by linking the analysis if your findings back to the theoretical framework and broader literature.

A number of changes were made to the manuscript in order to respond to the reviewers' comments regarding the results and discussion (/findings) section. These include: 
- Renaming of the section 'findings' rather than results and conclusion section

- In order to refocus the study and to allow for the additional information added to methods section we deleted the section on SIRC that was included in the original submission. The discussion regarding SIRC, whilst interesting, its deletion (in our view) does not necessarily retract from the overall argument/thread of the paper that explains how the CS4LLT were able to insert their ideas and reframe policy debates surrounding athlete development within Canada.

- The authors ensure that

Other consideration - First section of the paper regarding the background on the LTAD:

Although this study seems to focus on how the LTAD became intimately linked to the Canadian sport Policy and implemented through National Sport Organizations. The context of this linkages needs to be framed - in $\mathbf{2 0 0 0}$ there was significant concern over the poor international performances of Canadian athletes and their lack of preparation. See Kikulis 2013, Thibault \& Babiak, 2013 (in Thibault \& Harvey, editors, Sport Policy in Canada - in the author's reference list) for more context. As Haas suggests, "Decision makes do not always recognize that their understanding of complex issues and linkages is limited, and it often takes a crisis of shock to overcome institutional inertia and habit and spur them to seek help from an epistemic community (1992, p. 14).

The first section of the paper has also been reworked to respond to both reviewers' comments regarding the need to acknowledge the broader context in which LTAD has emerged. The trade-off here is between ensuring that the paper is sufficiently focused on the one hand whilst also acknowledging the wider context in which LTAD/CS4L has emerged on the other. As such, we have tried to incorporate a number of sentences in the first paragraph to acknowledge this broader context:

The framework has emerged primarily due to an increasing desire for many countries to ensure sustainable international sporting success (De Bosscher, De Knop, Van Bottenburg, \& Shibli, 2006) but also in an attempt to respond to the growing obesity epidemic. Within Canada, for example, the adoption of the LTAD framework by government occurred, in part, to attempt to respond to and realize the excellence and participation goals of the Canadian Sport Policy 1 (CSP1; 2002-2012), Canada's first national sport policy with bi-lateral agreements between the Federal and Provincial/ Territorial (F-P/T) Governments of Canada, and its successor policy, Canadian Sport Policy 2 (CSP2; 2012-2022) (Thibault \& Harvey, 2013; see also Comeau, 2013 for a specific discussion on the evolution of Canadian sport policy). In recent years, many sport organizations within Canada and other countries such as the United Kingdom and Australia have adopted the LTAD framework as the organizing framework for developing athletes to the extent that it could be described as the "new orthodoxy' in athlete development.

This broader context in which the CS4LLT and LTAD has emerged is also discussed at length on the bottom of page 15 in relation to LTAD/CS4L's emergence and development:

From this perspective, the emergence and development of the CS4LLT should be contextualized within the broader political developments that were occurring within Canadian sport at the time. Not only has Canadian sport historically been characterized as a highly fragmented pluralist network (Barnes et al., 2007; Comeau, 2013), but CSP1 (2002- 
2012) emerged, in part, to attempt to 'deal' with ongoing broader tensions regarding the role of federal-provincial/territorial governments' in sport and sport organizations and the ongoing debate regarding whether or not Canada should continue to prioritize high performance sport over other social objectives (Green \& Houlihan, 2005; Thibault \& Harvey, 2013). These broader tensions would have been brought into focus during the CSP1 policy process and given further impetus as a result of Canada's successful bid to host for the XXI Olympic Winter Games. In relation to the CS4LLT specifically, these broader historical tensions and contemporary policy-related developments would have contributed to the creation of a permissive climate in which decision-makers would have been particularly susceptible to ideas surrounding increasingly policy-relevant and high politics issues such as how best to systematically develop high performance athletes.

In addition, this concern about athlete development was explored by Sotiriadou and Shilbury in 2008 and 2009 in the Australian context and Houlihan in the British Context. And finally, although coaches might be considered an epistemic community - there has been alternative consideration of athlete development that have been argued as important - see the work of Jean Cote and company. It might be worthy of contextualizing athlete development in the broader sport policy literature and how others have considered this complex policy issue.

As per reviewer 1's suggestion, we have incorporated a number of additional sport policy sources to the article to acknowledge this. See reviewer 1 first comment response.

Closer attention to APA - referencing; there are sources listed that are not cited; there is no abstract provided (again note the criteria of APA that guides publication in the Journal of Sport Management).

The authors have re-checked the manuscript for any sources that were either not cited in the manuscript or bibliography.

The abstract was included in the original submission and we are not sure why the reviewer did not receive this. Nonetheless, we have re-attached the abstract to the main document submission to ensure it is received by the reviewer.

We also further developed and articulated the specific contributions of the paper in the last paragraph of the introduction. These contributions are also articulated in the conclusion section of the paper.

Overall I sense that there is a rich source of data - I would encourage the author to spend some time shaping their work for an academic article by closely considering refining their purpose and rationale for the study in the front section of the paper - as suggested there has been little consideration of the "technical" side of sport in the high performance sport sector and how it has shaped policy. The author points to a particular important mechanism for this that is also international in character, the LTAD as such the epistemic community approach, developed for international policy and also applied domestically, is particularly relevant - I encourage the authors to develop this framework in an effort to ensure their work can make a valuable contribution to the academic literature. In addition, for this empirical work to be considered equal attention needs to be given to articulating the methods

We would like to thank the reviewer for your helpful comments which we think have strengthened, focused and further clarified the contribution of the article. 